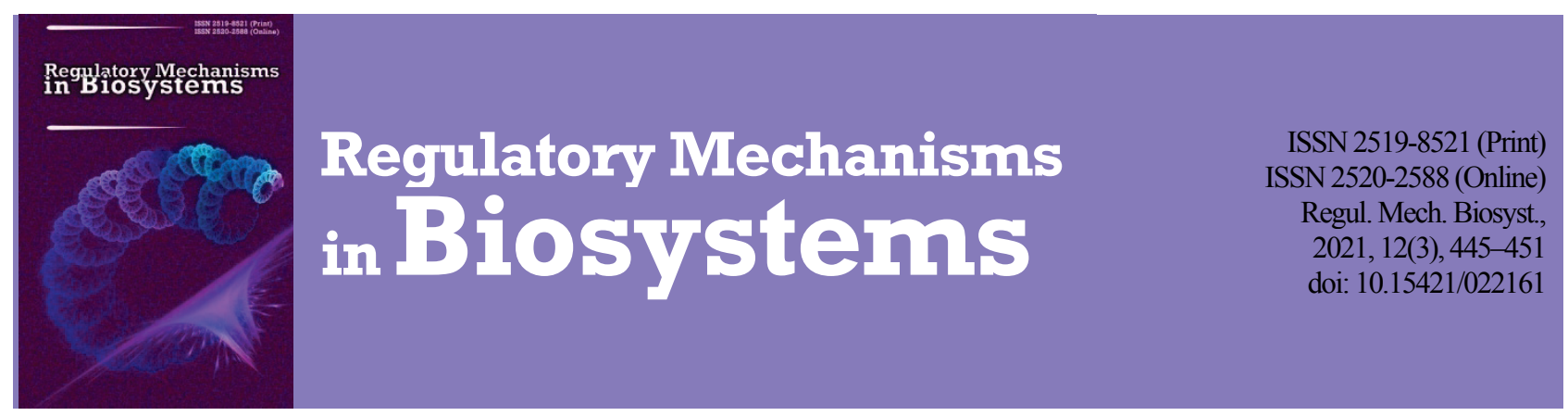

\title{
Hereditary tubulopathies accompanying polyuia
}

\author{
M. O. Ryznychuk*, V. P. Pishak**, N. V. Bacyuk-Ponych*, O. V. Pishak*** \\ *Bukovinian State Medical University, Chernivtsi, Ukraine \\ **National Academy of Pedagogical Sciences, Kyiv, Ukraine \\ ***Yuriy Fedkovich Chrnivtsi National University, Chernivtsi, Ukraine
}

Article info

Received 02.07.2021

Received in revised form 05.08.2021

Accepted 07.08.2021

Bukovinian State Medical University, Teatralnava sq., 2, Chernivtsi, 58001

Ukraine. Tel.: +38-050-192-09-53.

E-mail:

rysnichuk.mariana@gmail.com

National Academy of Pedagogical Sciences of Ukraine,

Sichovykh Streltsiv st., $52 A$

Kyiv, 04053, Ukraine

Tel.: +38-095-884-76-58.

E-mail:pishakvp@gmail.com

Yuriy Fedkovich Chrnivtsi National University, Kotsubinsky st., 2

Chernivtsi, 58001, Ukraine

Tel.: +38-050-507-09-57.

E-mail:o.pishak@chnu.edu.ua Ryznychuk, M. O., Pishak, V. P., Bacyuk-Ponych, N. V., \& Pishak, O. V. (2021). Hereditary tubulopathies accompanying
polyuia. Regulatory Mechanisms in Biosystems, 12(3), 445-451. doi:10.15421/022161

Tubulopathies are a group of heterogeneous diseases that are manifested in the malfunction of the renal tubules. This review addresses tubulopathies associated with polyuria syndrome, namely renal glucosuria syndrome, nephrogenic diabetes insipidus and pseudohyperaldosteronism. Types of renal glucosuria are described, namely: type A, type B and the most severe type 0 . Type $\mathrm{A}$ is characterized by a low filtration threshold and low glucose reabsorption. The type of inheritance is autosomal recessive. Type B, autosomal dominant, is characterized by uneven activity of glucose transport, in which its reabsorption is reduced only in some nephrons. That is, normal reabsorption of glucose is maintained, but the filtration threshold of the latter is reduced. Type 0 with a severe course is characterized by complete inability of epithelial cells of the proximal tubules to reabsorb glucose. Nephrogenic diabetes insipidus is a rare inherited disease caused by impaired response of the renal tubules to antidiuretic hormone (ADH). Depending on the degree of inability to concentrate urine, there are complete and partial forms. It is divided into nephrogenic diabetes insipidus type I (X-linked recessive); nephrogenic diabetes insipidus type II (autosomal recessive and autosomal dominant) and nephrogenic diabetes insipidus syndrome with dementia and intracerebral calcifications (type of inheritance remains unknown). Children with autosomal recessive type of inheritance suffer from the more severe disease course. Pseudohypoaldosteronism is characterized by a special condition of the renal tubules which is due to insufficient sensitivity of the tubular epithelium to aldosterone, which in turn leads to hyperaldosteronism, the development of hyponatremia, metabolic acidosis with hyperkalemia, polydipsia and polyuria, decreased sodium reabsorption and retardation of the child's physical development. The classification includes three syndromes of pseudohypoaldosteronism, namely: type I(PHA1), which is divided into PHA1A (autosomal dominant, renal), PHA1B (autosomal recessive, systemic); type II (PHA2; Gordon's syndrome), type III (secondary), which develops as a result of renal pathology.

Keywords: renal glucosuria; nephrogenic diabetes insipidus; pseudohypoaldosteronism; children; genes.

\section{Introduction}

Over the recent years, occurrence of renal pathology among children has increased. The kidneys are the organs that ensure the homeostasis stability in the body. The main function of the kidneys is regulating the circulatory volume through the control of sodium and water balance, thus maintaining extracellular fluid volume homeostasis; ensuring the concentration stability of osmotically active substances and individual ions in them, $\mathrm{pH}$ of the blood, the excretion of foreign substances. The incretory function of kidneys is associated with their role in renewal of the protein blood composition, the production of glucose, erythropoietin, renin, prostaglandins, active forms of vitamin $\mathrm{D}_{3}$. Kidney damage in childhood often causes the development of persistent hypertension in adults which leads to death from cardiovascular diseases (Barker et al., 1989; Vehaskart, 2007).

Tubulopathy is a group of diseases of various origins that manifest as dysfunction of the renal tubules. In primary or hereditary tubulopathies, impaired transport of substances through the renal tubules is associated with congenital defects of enzyme systems or inferiority (dysplasia) of cell membranes (Wright et al., 2007).

Depending on the nature and severity of tubular transport disorders, clinical signs of tubulopathies may manifest both in the first weeks of life and at a later age. Despite the variety of tubulopathies, they clinically manifest by different combinations of symptoms such as: hypertension/ hypotension, polyuria, polydipsia, rickets-like skeletal changes, physical retardation, as well as metabolic disorders such as acidosis/alkalosis and also pathology of sodium/potassium and potassium/phosphorus homeo- stasis (Lojman et al., 2010). Courses of some types of tubulopathies take place without severe disorders of homeostasis and require no specific therapy (e.g. renal glucosuria) (Prié, 2014). However, most primary tubulopathies are already manifested in infancy by increased excitability, vomiting, unexplained rises in body temperature due to electrolyte disorders. These symptoms are often interpreted by district pediatricians as manifestations of other diseases. By the time of diagnosis and treatment, recurrent episodes of dehydration with hypernatremia are possible, leading to seizures and mental retardation. Often, primary tubular dysfunction is complicated by urinary tract infection and children receive long courses of antibacterial therapy without a lasting effect. Severe polyuria (in nephrogenic diabetes insipidus) can cause dilation of the urinary tract (due to excessive urine volume) and the development of renal failure. Therefore, it is very important to suspect and recognize in time the relevant metabolic disorders associated with renal tubular dysfunction in order to prevent severe complications and ensure normal physical and neuropsychological development of the child (Osmanov et al., 2018).

This review examines hereditary tubulopathies that are accompanied by polyuria, namely renal glucosuria, nephrogenic diabetes insipidus and pseudohypoaldosteronism.

\section{Renal glucosuria (OMIM No. 233100)}

Renal glucosuria is a disease caused by impaired glucose transport in the proximal tubules of the kidneys, with normal blood glucose levels (Prié, 2014; Santer \& Calado, 2010). 
By the mid-1950s, renal titration studies divided renal glucosuria into type A and type B (Lewis \& Wolstenhome, 1954). Patients with renal glucosuria type A are characterized by low renal glucose threshold and low maximal tubular glucose reabsorption in contrast to patients with renal glucosuria type B who have low glucose threshold but can still achieve normal maximal tubular reabsorption, causing abnormal filtration-resorption curve. Later, the complete absence of renal glucose transport was found in a very small number of people and was marked as glucosuria type 0 (Oemar et al., 1987). Quantitative determination of glucose levels in the collected urine 2-4 hours after a $50 \mathrm{~g}$ glucose loading test in representatives of three pedigrees gave the first idea that the inheritance type for renal glucosuria may be dominant: people presumably homozygous for the condition had persistent severe glucosuria whereas heterozygous ones had a mild course (or no glucosuria at all) and had only "signs of renal glucosuria" (Khachadurian \& Khachadurian, 1964). Elsas \& Rosenberg (1969) reported that renal glucosuria of both type A and type B can occur in the same family and that both parents may be completely normal or have impaired renal tubular glucose transport. They suggested that this may be due to variable expression of the dominant mutation or, alternatively, caused by two different mutant genes in one person.

Under physiological conditions, glucose is completely reabsorbed in the proximal tubules in the S1 and S2 segments with the participation of the renal-specific sodium-glucose transporter-2 of the luminal membrane.

The remaining glucose is removed from the filtrate in the $\mathrm{S} 3$ segment by sodium-glucose transporter-1. This transporter is also present in the small intestine. Like other membrane transport systems, glucose transporters have a saturation limit. When the renal threshold for glucose is lowered, despite normal blood sugar levels, renal glucosuria occurs (Lee, 2013; Yu et al., 2015).

Renal glucosuria is characterized by the presence of hereditary defect in the enzyme systems of the proximal renal tubules which provide glucose reabsorption; this leads to increase in daily glucose excretion to 10 $20 \mathrm{~g}$, and can reach $100 \mathrm{~g}$ (physiological rate of glucose excretion is $200 \mathrm{mg}$ per day). The frequency of renal glucosuria is 2-3:1000.

General criteria for renal glucosuria are:

1) increased glucose excretion with normal or low blood sugar;

2) independence of glucose excretion in urine from carbohydrate intake; glucose excretion is at constant level both during the day and at night;

3) no changes in blood sugar levels with carbohydrate intake;

4) identification of sugar excreted in the urine as glucose;

5) normal sugar curve after glucose loading.

Renal glucosuria can be of three types:

- type A is characterized by decrease in the anatomical mass of the proximal tubules relative to the glomerular surface. Low filtration threshold and reduced glucose reabsorption are evident; the clinical picture will include:

- dehydration in the absence of sufficient fluid intake;

- polydipsia;

- hypokalemia;

- hypoglycemia or normoglycemia;

- delay in physical development;

- normal results of glucose tolerance test;

- glucosuria 16-27 g/day (the degree of glucosuria does not depend on the intake of glucose with food; glucosuria is unchangeable through the day and night);

- polyuria;

- type B is characterized by uneven activity of glucose transport, when its reabsorption is reduced only in part of the nephrons (along which there are nephrons with high intensity of glucose transport into the cell). That is, normal reabsorption is maintained, but the glucose filtration threshold is reduced (normoglycemia); the clinical picture is characterized by the presence of:

- normoglycemia;

- glucosuria 4.0-6.5 g/day.

- normal results of glucose tolerance test (Li et al., 2019).

Type 0 is extremely rare. The ability of epitheliocytes of the proximal tubules to reabsorb glucose is completely absent. Development of glucosuria is associated with a mutation that causes the absence or significant defect of tubular proteins that transport glucose, and as a result, complete loss of function in its reabsorption. These patients are seen to have high values in glucosuria. Therefore, the clinical manifestations will be severe and characterized by the presence of:

- dehydration in case of insufficient fluid intake;

- polydipsia;

- hypokalemia;

- hypoglycemia;

- delayed physical development;

- flattened glycemic curve (glucose tolerance test);

- glucosuria up to $100 \mathrm{~g} /$ day;

- polyuria;

- predisposition to the development of type 1 diabetes mellitus.

Type of inheritance remains unknown.

Differential diagnosis of renal glucosuria should be made taking into account the conditions or diseases that are accompanied by glucosuria, namely (Urakami et al., 2018):

-type 1 and 2 diabetes mellitus;

- diabetes type MODY;

- "steroid diabetes" with the use of glucocorticoids for therapeutic purposes;

- administration of infusion solutions (glucose dextrose solution);

- parenteral nutrition;

- acute tubular necrosis (interstitial nephritis);

- toxic kidney damage;

- transient glucosuria of pregnant women;

- glucose/galactose malabsorption;

- Albright-Butler-Bloomberg syndrome (requires a mandatory study of the excretion amount of phosphates and amino acids in each patient with renal glucosuria);

- congenital nephrosis;

- Lowe syndrome (oculocerebrorenal);

- glucoglycinuria syndrome;

- De Toni Debré Fanconi syndrome;

- some cases of autosomal dominant tubulopathy are accompanied by glycinuria and glucosuria. Patients often suffer from cystic fibrosis.

Treatment. There are no methods of pathogenetic therapy of this disease. It is important to ensure proper patient's nutrition to avoid carbohydrate overload and hyperglycemia, which contribute to increased sugar loss. With the development of hypoglycemia, it may be necessary to introduce additional glucose, and in the conditions of hypokalemia, it is advisable to introduce products that contain large amounts of potassium (raisins, carrots, etc.). The prognosis is favourable. Prevention lies in medical and genetic counseling. Type of inheritance may be autosomal recessive (glucose loss up to 16-27 g/day, severe type A); or autosomal dominant (glucose loss up to 4.0-6.5 g/day, type B). Mutation of the SLC5A2 gene of sodiumglucose cotransporter-2 (SGLT2) is evident on chromosome 16p11.2.

\section{Nephrogenic diabetes insipidus (vasopressin-resistant diabetes insipidus)}

Nephrogenic diabetes insipidus is a rare inherited disease characterized by lack of permeability of collecting tubules for water and resistance to the action of $\mathrm{ADH}$ with its adequate secretion.

Renal diabetes insipidus (syn. nephrogenic) is caused by impaired response of the renal tubules to antidiuretic hormones (ADH). Depending on the degree of inability to concentrate urine, there are full and partial forms. Primary (congenital) forms are associated with mutations in the gene of the vasopressin $V_{2}$ receptor in the collecting renal tubule or the gene encoding the collector system of water tubules, i.e. aquaporin-2.

As a rule, secondary (acquired) forms are partial as a result of disturbances of rather high osmotic pressure in the brain substance of kidneys (phases of polyuria after acute necrosis of the renal tubules, pyelonephritis, obstructive nephropathy, cysts of the renal medulla, multiple myeloma, renal amyloidosis, sickle cell anemia, renal transplant rejection), or due to decreased sensitivity to vasopressin receptors in the renal tubules (hypokalemia, hypercalcemia).

Congenital forms are divided into:

- nephrogenic diabetes insipidus type I (linked to the X chromosome, recessive); 
- nephrogenic diabetes insipidus type II (autosomal dominant and autosomal recessive);

- nephrogenic diabetes insipidus syndrome with dementia and intracerebral calcifications.

Recommended examinations for diagnosing nephrogenic diabetes insipidus:

- acid-base balance (blood $\mathrm{pH}, \mathrm{HCO}_{3}^{-}, \mathrm{BE}$ );

- relative urine density measurement, plasma osmolarity, urine osmolarity;

- biochemical analysis of blood: sodium, chlorides, potassium, creatinine, urea, glucose;

- test with exogenous $\mathrm{ADH}$ : the goal of the test is to determine the response of the renal concentration mechanism to the introduction of exogenous vasopressin $(\mathrm{ADH})$. Children under one year of age are subjected to this test in exceptional cases.

Urine osmolarity after drug administration should increase to 800 $900 \mathrm{mOsm} / \mathrm{kg}$ (density up to $1020-1025$ ) in sequentially collected urine tests. The lack of increased osmolarity and relative density of urine confirms the resistance of the collecting tubules to the action of $\mathrm{ADH}$, which is characteristic of nephrogenic diabetes insipidus.

Diagnostic criteria are as follows:

- general analysis of urine: persistent hypostenuria (low relative density of urine 1001-1004, low osmolarity of urine - less than $250 \mathrm{mOsm} / \mathrm{kg}$ ), no protein and glucose, normal sediment;

- plasma hyperosmolarity $>300 \mathrm{mOsm} / \mathrm{kg}$;

- hypernatremia.

Ultrasound of the kidneys is recommended: in the conditions of constant excretion of large amounts of urine contributes to hypotension and dilatation of the collecting system of the kidneys, ureters and bladder. Differential diagnosis of nephrogenic diabetes insipidus is performed with:

- primary polydipsia;

- central diabetes insipidus;

- osmotic diuresis due to diabetic hyperglycemia.

In these conditions, the test with the injection of antidiuretic hormone $(\mathrm{ADH})$ causes increase in osmolarity and urine density. It is possible to use the test with fluid restriction. An aqueous deprivation test should never be performed in the presence of hypernatremia or elevated plasma osmolarity. In these situations, as well as in some cases in infants, a paired analysis of the urine osmolarity and plasma is sufficient.

Primary polydipsia, or psychogenic polydipsia, occurs in patients with mental disorders. Excessive fluid intake (up to $12 \mathrm{~L} /$ day) is characteristic, leading to decrease in plasma osmolarity $(240-280 \mathrm{mOsm} / \mathrm{kg}$ ). Inhibition of $\mathrm{ADH}$ secretion is accompanied by decrease in its concentration in blood plasma and decrease in water reabsorption in the distal nephron. Until the plasma osmolarity increases to normal, a large amount of diluted urine is excreted (urine osmolarity less than $250 \mathrm{mOsm} / \mathrm{kg}$, density less than 1005).

Patients with central diabetes insipidus who have access to water, with the preserved mechanism of thirst will show presence of polyuria (urine osmolality less than $250 \mathrm{mOsm} / \mathrm{kg}$, relative density less than 1005 1007), polydipsia and normal plasma osmolarity (280-295 mOsm/kg).

There is a number of other diseases accompanied by damage to the renal tubules and interstitium with polyuria and polydipsia. These are distal renal tubular acidosis, cystinosis, nephronophthisis, obstructive uropathy, renal amyloidosis, sickle cell nephropathy, Sjogren's syndrome, myeloma kidney and nephropathy in lung chain disease; nephropathy caused by lead poisoning; drug-induced damage (lithium salts, cidofovir, amphotericin B). Diuresis in these cases does not exceed $3.5 \mathrm{~L} / \mathrm{m}^{2} /$ day.

\section{Nephrogenic diabetes insipidus type I (OMIM No. 304800)}

$\mathrm{X}$-linked recessive form is evident due to mutations in the AVPR2 gene (locus $\mathrm{Xq} 28$ ), which encodes arginine vasopressin receptor $\left(\mathrm{V}_{2} \mathrm{R}\right)$ in cells of the collecting tubules. Activated by binding to vasopressin, the $V_{2}$ receptor causes increase in cAMP. This leads to the movement towards the apical membrane of intracellular vesicles containing aqueous channels of aquaporins-2 (AQ-2), increasing the permeability of the tubules to water. A genetic defect involving different numbers of mutations in the $V_{2}$ receptor gene results in decreased vasopressin binding to the receptor, decreased synthesis or increased degradation of the receptor itself. As a result, the action of $\mathrm{ADH}$ becomes blocked. Various mutations are associated with variable resistance to $\mathrm{ADH}$. X-linked inheritance variant involves the presence of severe polyuria in boys; in females, polyuria can occur during pregnancy, when the secretion of placental vasopressinase leads to increased clearance of endogenous ADH (Morello \& Bichet, 2001).

According to the literature, $\mathrm{X}$-linked recessive type of inheritance occurs in $90 \%$ of all cases of hereditary nephrogenic diabetes insipidus (Geary \& Schaefer, 2008). There are many different mutations in the AVPR2 gene which disrupt receptor signals and lead to insensitivity of the $\mathrm{V}_{2}$ receptors of the basal cell membranes of the collecting tubes to ADH. Taking into account the molecular mechanisms of $\mathrm{V}_{2} \mathrm{R}$ insensitivity to $\mathrm{ADH}$, there have been identified classes of mutations in nephrogenic diabetes insipidus in the cell model (Geary \& Schaefer, 2008; Lifton et al., 2009; Li et al., 2019). Symptoms of nephrogenic diabetes insipidus with $\mathrm{X}$-linked inheritance mostly manifest in males, and sometimes heterozygous females show symptoms of nephrogenic diabetes insipidus depending on the presence of different activation of the mutated gene - Lion mechanism (Geary \& Schaefer, 2008; Avner et al., 2009; Lifton et al., 2009; Bichet \& Bockenhauer, 2016).

The clinical cases occur due to the inability of the combined renal tubules to reabsorb water in response to $\mathrm{ADH}$ which is accompanied by:
-vomiting;
- anorexia;
- fever;
- constipation;
- polydipsia;
- polyuria;
- growth retardation;
- hydronephrosis often occurs;
- possible convulsive conditions;
- the disease manifests in the first two years of life.

\section{Nephrogenic diabetes insipidus type II (OMIM No. 125800)}

The basis of autosomal dominant and autosomal recessive forms of nephrogenic diabetes insipidus lies in mutations in the AQP2 gene mapped on autosome 12q13.12. AQP2 gene encodes aquaporin-2 water channel, located on the apical cell membrane of the renal collecting tubules (Geary \& Schaefer, 2008; Avner et al., 2009; Lifton et al., 2009; Bichet \& Bockenhauer, 2016). Autosomal inheritance with autosomal recessive and autosomal dominant subtypes occurs in $10 \%$ of all cases of hereditary nephrogenic diabetes insipidus (Geary \& Schaefer, 2008; Lifton et al., 2009; Bichet \& Bockenhauer, 2016). Both boys and girls may suffer from it. Postreceptor defect is a disorder in movement and subsequent fusion with the luminal membrane of $\mathrm{ADH}$-sensitive water channels of aquaporins- 2 which are localized in the cytoplasm of the main cells of the collecting tubules, thereby preventing passive diffusion of water.

In autosomal dominant nephrogenic diabetes insipidus, clinical symptoms of polyuria and polydipsia appear in infants and school-aged children. An experiment on rats has shown that the drug exposure may increase the expression of AQP2 in the apical plasma membrane of the collecting tubules (Klein et al., 2016).

Type of inheritance may be autosomal recessive and autosomal dominant. The disease is more severe in children with autosomal recessive type of inheritance (Morello \& Bichet, 2001).

The clinical picture is characterized by:

- hypernatremia;

- severe dehydration;

- low osmotic pressure of urine;

- "salt fever";

- feeding difficulty;

- delayed physical development;

- vomiting;

- anorexia;

- polyuria;

- polydipsia;

- possible convulsive conditions;

- manifestation from the first days of life. 
Nephrogenic diabetes insipidus syndrome with dementia and intracerebral calcifications (OMIM No. 221995)

The clinical picture is characterized by:

- dwarfism;

- the presence of intracerebral calcifications;

- hypernatremia;

- severe dehydration;

- low osmotic pressure of urine;

- "salt fever";

-vomiting;

- anorexia;

- polyuria;

- polydipsia;

- possible convulsive conditions;

- manifestation from the first days of life;

- development of mental retardation or dementia (Ocal et al., 2001; Schofer et al., 1990).

It should be differentiated from Cockayne syndrome.

Patients with polyuria, polydipsia should be examined by a nephrologist, endocrinologist and clinical geneticist.

The diagnosis of nephrogenic diabetes insipidus is based on the typical clinical manifestations of polyuria, polydipsia, hypostenuria from infancy. Increased Na plasma (greater than $145 \mathrm{mmol} / \mathrm{L}$ ), low relative density (1001-1003) and osmolarity of urine (less than $200 \mathrm{mOsmol} / \mathrm{kg} \mathrm{H}_{2} \mathrm{O}$ ) in children with polyuria and polydipsia are important criteria for the diagnosis of nephrogenic diabetes insipidus. The diagnosis requires results of genealogical analysis, differential diagnostic tests with DDAVP (synthetic analogue of $\mathrm{ADH}$ ) and molecular genetic studies.

Differential diagnostic tests with DDAVP-synthetic analogue of $\mathrm{ADH}$ are performed for the differential diagnosis of nephrogenic diabetes insipidus and neurohypophyseal diabetes insipidus as well as psychogenic polydipsia.

Children under one year of age have a physiological decrease in the sensitivity of $V_{2}$ receptors to $A D H$, so it is not recommended to perform test with DDAVP.

Nephrogenic diabetes insipidus is diagnozed using:

1) urine test by Zymnytsky method (hypo- and isostenuria, specific density of urine - 1001-1005);

2) daily urine - polyuria;

3) test with fluid restriction (test with dry food, dehydration). The test is based on the fact that dehydration leads to increased blood osmolarity. Normally, vasopressin maintains blood plasma pressure is 285$287 \mathrm{mOsm} / \mathrm{kg}$. If the osmotic pressure decreases to $280 \mathrm{mOsm} / \mathrm{kg}$, the secretion of vasopressin is suppressed, and vice versa, an increase in osmotic pressure higher than $288 \mathrm{mOsm} / \mathrm{kg}$ leads to stimulation of vasopressin synthesis and to the maximum concentration of urine.

The test is performed exclusively in hospitals. After fasting at night, the patient's body weight, sodium levels, blood urea nitrogen, specific urine density and sodium content in the urine are determined. After that, the patient stops drinking fluids. The duration should not exceed $6-$ 8 hours, in exceptional cases -24 hours. The patient is weighed every hour, and blood sodium, volume, and specific urine density are measured. At the end of the test, it is advisable to determine the level of vasopressin in the plasma.

The test should be discontinued in cases of 3-5\% decrease in body weight, or increase in plasma sodium concentration above the upper threshold of the normal level (in patients with diabetes insipidus, usually within a few hours), or if the osmolarity of 2-3 regular portions of urine does not differ by more than $10 \%$, but plasma osmolarity increases; plasma osmolarity $>295-300 \mathrm{mOsm} / \mathrm{kg}$. If there are no indications before the end of the test, it should be extended to 18 hours to rule out diabetes insipidus.

Test with vasopressin (the second part of the dehydration - vasopressin test) differentiates central and nephrogenic diabetes insipidus. At the end of the dry food test, desmopressin $0.2 \mathrm{mg}$ per os or $20 \mu \mathrm{g}$ should be administered intranasally (table) and the specific gravity and osmolarity of all urine portions should be determined.

Differential diagnosis of diabetes insipidus is not particularly difficult. In addition to neurohypophyseal diabetes insipidus, it is necessary to keep in mind polyuria, which develops in patients with diabetes mellitus as a consequence of hyperosmotic diuresis and diseases accompanied by fever or tubulopathies with polyuria.

\section{Table}

Differential diagnosis of psychogenic polydipsia, central and nephrogenic diabetes insipidus

\begin{tabular}{lccc}
\hline \multicolumn{1}{c}{$\begin{array}{c}\text { Test } \\
\text { scores }\end{array}$} & $\begin{array}{c}\text { Psychogenic poly- } \\
\text { dipsia }\end{array}$ & $\begin{array}{c}\text { Central } \\
\text { diabetes insipidus }\end{array}$ & $\begin{array}{c}\text { Nephrogenic } \\
\text { diabetes insipidus }\end{array}$ \\
\hline $\begin{array}{l}\text { Specific density } \\
\text { of urine }\end{array}$ & $\begin{array}{c}\text { gradually } \\
\text { increasing } \\
\text { gradually appro- } \\
\text { aching the norm } \\
\text { initially low, } \\
\text { but increasing }\end{array}$ & $<250 \mathrm{mOsm} / \mathrm{kg}$ & $<250 \mathrm{mOsm} / \mathrm{kg}$ \\
$\begin{array}{l}\text { Urine osmolarity } \\
\begin{array}{l}\text { Concentration of va- } \\
\text { sopressin in plasma }\end{array}\end{array}$ & low & high \\
\hline \multicolumn{4}{c}{ Vasopressin test (desmopressin $0.2 \mathrm{mg}$ per os) } \\
\hline $\begin{array}{l}\text { Specific gravity } \\
\text { of urine }\end{array}$ & $\begin{array}{c}\text { there are no indica- } \\
\text { tions for the test }\end{array}$ & $\begin{array}{c}\text { increase by } \geq 50 \% \\
(200-400 \%)\end{array}$ & $\begin{array}{c}\text { low, not } \\
\text { increasing }\end{array}$ \\
\hline
\end{tabular}

Treatment of nephrogenic diabetes insipidus is symptomatic and aimed primarily at maintaining electrolyte balance by injecting sufficient fluids. If the child refuses to drink fluids, as well as developing signs of dehydration, the fluid is administered intravenously, often using a 5\% glucose solution.

Balla \& Hunyady (2019) proved that thiazide diuretics have a paradoxical effect, i.e. reduce polyuria and increase the osmolarity of urine in nephrogenic diabetes insipidus. Thiazide therapy, the paradoxical effect of which is reducing fluid intake and urine output, has become standard in the treatment of children and adolescents with nephrogenic diabetes insipidus. Traditional therapy of children involves the prescription of thiazide diuretics (hypothiazide at a dose of $2-4 \mathrm{mg} / \mathrm{kg} /$ day) individually or in combination with a nonsteroidal anti-inflammatory drug (indomethacin), or in combination with a potassium-sparing diuretic amiloride (Balla \& Hunyady, 2016; Kavanagh \& Uy, 2019).

Constant monitoring of acid-base balance of the blood, as well as daily calciumuria, calcium and potassium levels in blood serum should be ensured during treatment with hypothiazide.

One should take into account that hypothiazide increases the reabsorption of calcium and magnesium in the tubules, causes the development of metabolic alkalosis and hypokalemia. Therefore, daily calciumuria, calcium and potassium levels in blood serum and acid-base balance (ABB) should be monitored in the process of hypothiazide therapy of children with nephrogenic diabetes insipidus.

In cases of combination therapy, the following schemes should be prescribed: hypothiazide in the dose of $1-2 \mathrm{mg} / \mathrm{kg} /$ day with indomethacin in the dose of $0.75-1.50 \mathrm{mg} / \mathrm{kg} /$ day or hypothiazide $2 \mathrm{mg} / \mathrm{kg} / \mathrm{day}$ and indomethacin $1.5 \mathrm{mg} / \mathrm{kg} /$ day or hypothiazide $2 \mathrm{mg} / \mathrm{kg}$ and indomethacin $2 \mathrm{mg} / \mathrm{kg}$, which requires potassium supplements to prevent hypokalemia (Jakobsson \& Berg, 1994). The mechanism of diuretic action of indomethacin is stimulating the synthesis of cyclic adenosine monophosphate (cAMP), increasing vasopressin-stimulated reabsorption of water in the collecting tubules, or increasing the reabsorption of $\mathrm{NaCl}$ in the thick ascending limb of Henle's loop.

In case of combination therapy with amiloride, following scheme should be prescribed: hypothiazide $3 \mathrm{mg} / \mathrm{kg} /$ day with amiloride $0.3 \mathrm{mg} / \mathrm{kg} /$ day (first amiloride, then after 2-3 hours hydrochlorothiazide). Hypothiazide therapy in combination with amiloride has been shown to reduce polyuria and polydipsia (Kilchlechner et al., 1999). Amyloride is a potassium-sparing diuretic that acts on the distal part of the renal tubules, increases urinary excretion of sodium and chlorine, and reduces the excretion of potassium ions. This combination therapy restores potassium balance and prevents the development of hypokalemia and requires no additional potassium administration.

Children with nephrogenic diabetes insipidus suffering from dehydration are prescribed oral and infusion therapy intravenously $5 \%$ solution of glucose and $0.9 \%$ physiological solution of sodium chloride in proportion $3: 1$, for children below 6 months of age it is $4: 1$.

Selective cyclooxygenase-2 (COX-2) inhibitors may be useful in cases of patients who have indomethacin intolerance. Care should be exercised when using indomethacin and selective COX-2 inhibitors with 
nephrogenic diabetes insipidus, as their administration has the potential to lead to sharp deterioration in renal function in patients with dehydration (Know et al., 1998). Experience with long-term use of cyclooxygenase inhibitors as monotherapy is limited (Knoers et al., 1990; Li et al., 2009; Miranda et al., 2014).

Recent studies using experiments on rats have shown that metformin increases the permeability of osmotic water by increasing the accumulation of AQP2 in the apical plasma membrane, but also increases the permeability of urea by activating the urea transporter UT-A1 in the membrane (Klein et al., 2006). Klein et al. concluded that activation of adenosine monophosphate kinase (AMPK) with the help of metformin activates many mechanisms that increase the ability of vasopressin to concentrate urinee. These data suggest that metformin may be a new treatment for congenital nephrogenic diabetes insipidus caused by $\mathrm{V}_{2}$ receptor mutations (2016)

Li et al. (2015) reported a selective EP4 agonist of the PGE2 receptor in the experiment as a new model of therapy of X-linked recessive nephrogenic diabetes insipidus (2009). Bockenhauer \& Bichet believe that the data on the independent activation of EP2 and EP4 agonists by PGE2 receptors increase the intriguing possibility of a new therapeutic pathway for patients with X-linked recessive nephrogenic diabetes insipidus. According to the authors, it remains unclear how to resolve the contradiction between the new data, as the blockade of prostaglandin synthesis by indomethacin therapy has actually proven clinical efficacy (Li et al., 2015).

Experimental studies have shown that selective phosphodiesterase inhibitor may be used in the treatment of children with X-linked recessive nephrogenic diabetes insipidus. Assadi \& Sharbaf (2015) reported that treatment with sildenafil, a selective phosphodiesterase inhibitor, may enhance cyclic guanosine monophosphate cGMP-mediated AQP2 transport and have the effect of increasing water reabsorption in patients with congenital nephrogenic diabetes insipidus. A child with X-linked recessive nephrogenic diabetes insipidus resistant to traditional therapy, showed a positive trend after being treated with sildenafil for 10 days. Compared with the traditional therapy, treatment with sildenafil resulted in significant reduction in 24-hour urine volume $(1764 / 950 \mathrm{~mL})$ and serum sodium $(148 / 139 \mathrm{mmol} / \mathrm{L})$, increased urine osmolarity (104 vs. $215 \mathrm{mOsm} / \mathrm{L})$, and AQP2 excretion ( 5 vs. $26 \mathrm{fmol} / \mathrm{mg}$ cr). Therapy with selective sildenafil phosphodiesterase inhibitor is considered as an alternative to other methods for children with X-linked recessive nephrogenic diabetes insipidus (Assadi \& Sharbaf, 2015).

In an experimental study, Cheung et al. (2016) demonstrated that erlotinib, a selective EGFR inhibitor, enhances AQP2 expression on the apical membrane of stem cells of the collecting tubules. In the experiment on mice with lithium-induced nephrogenic diabetes insipidus, erlotinib treatment lasting 5 days caused $45 \%$ decrease in urine volume. The results of the experimental studies suggested a new way of regulating AQP2mediated water reabsorption and a therapeutic strategy in cases of nephrogenic diabetes insipidus (Cheung et al., 2016).

Due to the possibility of developing hypertensive dehydration, some factors like febrile illnesses, moving to areas with hot climates, surgery are among serious risks to the patients' health, especially for young children.

Complications of nephrogenic diabetes insipidus in children and adolescents include dilatation of the cups and pelvis, ureter, bladder: megacystis, megaureter, hydronephrosis without signs of anatomical obstruction due to large volumes of daily urine and the formation of chronic kidney disease. The prognosis is relatively favourable. Prevention is medical and genetic counseling.

\section{Pseudohypoaldosteronism}

Fluid balance, sodium and potassium homeostasis and blood pressure are regulated by the action of aldosterone on polarized epithelial cells. The aldosterone signal is transmitted by the mineralocorticoid (MR) receptor, inducing the amiloride-sensitive epithelial sodium channel $(\mathrm{ENaC})$ as the leading intracellular factor required for sodium retention. Disruption of intracellular signaling pathways of mineralocorticoid receptors leads to the clinical picture of pseudohypoaldosteronism (PHA). Detection of molecular changes that cause pseudohypoaldosteronism contributed to the elucidation of intracellular factors responsible for salt homeostasis and to their interaction as an epithelial transport mechanism of sodium.

Pseudohypoaldosteronism (syn.: neprogenic salt diabetes, receptor hypoaldosteronism, congenital renal salt loss syndrome, pseudohypoadrenocorticism) belongs to a heterogeneous group of disorders of electrolyte metabolism and is characterized by a special condition of the renal tubules, which is caused by insufficient sensitivity of the tubular epithelium to aldosterone, which leads to hyperaldosteronism, decreased sodium reabsorption, the development of hyponatremia, metabolic acidosis with hyperkalemia, polyuria, polydipsia and physical retardation (Kuhnle, 1997).

The pathology belongs to hereditary diseases and occurs very rarely, which makes it difficult to make timely diagnosis and therefore provide early and effective treatment.

The current classification includes three syndromes of pseudohypoaldosteronism, namely: type I (PHA1), which is divided into PHA1A (autosomal dominant, renal), PHA1B (autosomal recessive, systemic); type II (PHA2; Gordon's syndrome), which is divided into PHA2A, PHA2B, PHA2C, PHA2D, PHA2E depending on the gene mutation; type III (secondary), which develops as a result of renal pathologies, such as nephropathy, urinary tract infections and obstructive uropathy (Maruyama et al., 2002; Dolezel et al., 2004).

All types are caused by resistance to mineralocorticoids due to impaired signaling.

Early childhood hyperkalemia is a variant of the renal form of pseudohypoaldosteronism type I, or Cheek and Perry syndrome, and is presented in the literature as the commonest form of childhood disease (Cheek \& Perry, 1958). The disease occurs in girls and boys with equal frequency.

PHA1 is characterized by neonatal salt loss, resistance to treatment with mineralocorticoids (Cheek \& Perry, 1958). Laboratory data revealed hyponatremia, hyperkalemia and metabolic acidosis. Elevated plasma concentrations of renin and aldosterone reflect insensitivity of the kidneys and other tissues to mineralocorticoids.

\section{Pseudohypoaldosteronism, type I autosomal dominant (PHA1A; OMIM No. 177735)}

Renal pseudohypoaldosteronism type I is most likely caused by impaired maturation of aldosterone receptors, which reduces their number and functional activity. This process is associated with a heterozygous mutation in the human mineralocorticoid receptor gene (MLR, NR3C2) on chromosome 4q31.23, which has autosomal dominant type of inheritance. This is an isolated renal resistance to aldosterone, which leads to salt loss by the kidneys, the development of hyponatremia, hyperkalemia, metabolic acidosis, delayed physical development, increased renin and aldosterone concentration in plasma (Geller, 2005). The most notable clinical sign is refusal to eat and insufficient weight gain due to chronic dehydration. Existing hyperkalemia is usually benign and mild, and metabolic acidosis is not always detectable. Patients are mostly diagnosed having it at an early age. Treatment is adding sodium, which is usually enough to reduce elevated potassium levels. Sodium administration usually becomes unnecessary after to 1-3 years (Cheek \& Perry, 1958), which is due to the maturation of renal tear-retaining properties and the replacement of distal sodium reabsorption on the proximal parts of the tubules. Occasionally, nephrocalcinosis and hypercalciuria are observed. Sometimes hyponatremia is not detected due to blood clotting.

In general, PHA1A is a milder form of PHA1 because salt loss is limited by the kidneys. The clinical spectrum varies from healthy patients without electrolyte disturbances, but with elevated levels of renin and aldosterone in plasma, to patients with clinically significant renal salt loss (Riepe et al., 2006). Elevated aldosterone is the only biochemical marker of PHA1A in adulthood (Geller et al., 2006).

\section{Pseudohypoaldosteronism, type I autosomal recessive (PHA1B; OMIM No. 264350)}

Systemic type, PHA1B, has autosomal recessive type of inheritance. Clinical manifestations most often occur in the neonatal period and are manifested by severe dehydration and hyponatremia due to systemic salt 
loss by the kidneys, colon, sweat and salivary glands. Increased sodium concentration in sweat and no difference between nasal or rectal transepithelial potential can be used as diagnostic means. Hyponatremia and hyperkalemia are combined with elevated plasma concentrations of renin and aldosterone, which reflects the resistance of the targeted organs. Due to increased concentration of salt in the mucous membrane of the respiratory organs, there is a risk of infection and involvement in the pathological process of the lower respiratory tract. The course of the disease resembles lung pathology with fibrocystic transformations (Kerem et al., 1999).

Clinically, it may manifest in cough, fever, tachypnea, and presence of wheezing in lungs during auscultation (Kerem et al., 1999; Schaedel et al., 1999). Interestingly, neonatal respiratory distress syndromes have not been reported in patients with PHA1B. PHA1B is a lifelong disease and the condition of people suffering it do not improve over time (Zennaro \& Lombes, 2004). Patients are prone to life-threatening crises due to salt loss in combination with severe hyperkalemia and dehydration. The treatment is prescribing large doses of salt. Additional measures include the use of agents that reduce potassium levels.

PHA1B is caused by a homozygous or heterozygous mutation in any of the three genes encoding epithelial sodium channel subunits $(\mathrm{ENaC})$ : alpha subunit (SCNN1A), beta subunit (SCNN1B) or gamma subunit (SCNN1G).

Pseudohypoaldosteronism type II (PHA2; known in the literature as Gordon's syndrome) is a renal tubulopathy characterized by hypertension and hyperkalemia, metabolic acidosis with reduced renin and aldosterone levels in plasma, and it is well corrected by thiazide diuretics. The disease is extremely rare and occurs in older children or adults when there is a tendency for high blood pressure. In 1964, the first case of PHA2A (OMIM No. 145260) was reported by Paver \& Pauline (1964). It was described by Gordon (1970) as a disease with signs of muscle weakness and the development of recurrent paralysis. Severe consequences of pseudohypoaldosteronism include death from cardiac arrhythmia as a result of significant hyperkalemia, nephrocalcinosis, and nephrolithiasis.

Depending on the genes mutation, PHA2 is divided as follows: PHA2A (OMIM No. 145260) caused by mutation of the first chromosome 1q31-q42; PHA2B (OMIM No. 614491) caused by mutations in the WNK4 gene on chromosome 17q21; PHA2C (OMIM No. 614492) caused by mutations in the WNK1 gene on chromosome 12p13; PHA2D (OMIM No. 614495) caused by mutations in the KLHL3 gene on chromosome 5q31 and PHA2E (OMIM No. 614496) caused by mutations in the CUL3 gene on chromosome 2q36 (Boyden et al., 2012).

By type of inheritance PHA2 can be divided into autosomal dominant types PHA2A, PHA2B, PHA2C, PHA2E, and type PHA2D can be inherited in both autosomal dominant and autosomal recessive ways.

According to the pathogenesis, there are also primary and secondary pseudohypoaldosteronism. The primary one is inherited by autosomal recessive or autosomal dominant type, the secondary one develops in some kidney diseases: pyelonephritis, polycystic kidney disease and others. In patients with primary pseudohypoaldosteronism, no morphological changes in renal tissue are detected. Clinical manifestations of primary pseudohypoaldosteronism are due to the refractoriness of the distal tubules to aldosterone. The symptoms of the disease can vary even among members of the same family with the same genetic defect. Serious signs of the disease (anorexia, vomiting, etc.) can occur immediately after birth, in the first two weeks of life or no symptoms at all may manifest. Secondary pseudohypoaldosteronism can occur at any age with various pathologies (Smijan et al., 2010).

Among the basic principles of pseudohypoaldosteronism therapy, we should distinguish the following aspects. It is recommended to introduce an isotonic solution of sodium chloride and liquid. The dose of salt can reach $3 \mathrm{~g} /$ day and depends on the loss of sodium in the urine. Additional salt intake in infancy can completely correct hyponatremia and hyperkalemia. After 2-4 years, the need for additional sodium chloride disappears, children's physical development improves. When feeding the patients, attention should be paid to the exclusion of foods that contain potassium $(0.6 \mathrm{mg} / \mathrm{kg} /$ day $)$ and elevated sodium levels $(10-15 \mathrm{mg} / \mathrm{kg} /$ day $)$. Patients with severe hypovolemia and shock are prescribed infusion therapy using isotonic sodium chloride solution in the dose of $20 \mathrm{~mL} / \mathrm{kg}$ of body weight. High potassium levels require intravenous injection of $10 \%$ calcium glu- conate solution $(0.5-1.0 \mathrm{~mL} / \mathrm{kg}), 5 \%$ glucose solution with insulin. Drugs should be prescribed taking into account the type of pseudohypoaldosteronism. Preparations of deoxycorticosterone acetate, deoxycorticosterone trimethylacetate, fluorohydrocortisone acetate are ineffective in pseudohypoaldosteronism treatment.

\section{Conclusions}

Diagnosis of tubulopathies with polyuria syndrome is difficult, but the following tests may suggest a rather complex genetic pathology. With renal glucosuria, the child is diagnosed with polyuria, polydipsia, normoglycemia and glucosuria of varying severity. Persistent hypostenuria (low relative density of urine 1001-1004, low urine osmolarity - less than $250 \mathrm{mOsm} / \mathrm{kg}$ ), no protein and glucose, normal sediment, plasma hyperosmolarity $>300 \mathrm{mOsm} / \mathrm{kg}$, blood hypernatremia can be found with nephrogenic diabetes insipidus. Ultrasound of kidneys is recommended because it detects hypotension and dilatation of the collecting system of the kidneys, ureters and bladder.

Pseudohypoaldosteronism is detected on the basis of presence of hyponatremia, hyperkalemia and metabolic acidosis. Plasma concentrations of renin and aldosterone are elevated, reflecting the insensitivity of kidneys and other tissues to mineralocorticoids. Detection of pathological data by means of laboratory methods of examination requires molecular genetic research to chose treatment tactics and prognosis.

\section{References}

Assadi, F., \& Sharbaf, F. G. (2015). Sildenafil for the treatment of congenital nephrogenic diabetes insipidus. American Journal of Nephrology, 42(1), 65-69.

Avner, E. D., Harmon, W. E., Niaudet, P., \& Yoshikawa, N. (Eds.) (2009). Pediatric nephrology: 6th edition. In: Knoers, N., \& Levtchenko, E. N. (2009). Nephrogenic diabetes insipidus. Springer-Verlag, Berlin, Heidelberg. Vol. 1. Pp. 1005 1018 .

Balla, A., \& Hunyady, L. (2019). Nephrogenic diabetes insipidus. Experientia, Supplementum, 111,317-339.

Barker, D. J. P., Osmond, C., Golding, J., Kuh, D., \& Wadsworth, M. E. J. (1989). Growth in utero, blood pressure in childhood and adult life, and mortality from cardiovascular disease. British Medical Journal, 298, 564-567.

Bichet, D. G. (2009). Nephrogenic diabetes insipidus: Vasopressin receptor defect. In: Lifton, R. P., Somlo, S., Giebsch, G., \& Seldin, D. W. (Eds.). Genetic diseases of the kidney. Elsevier. Pp. 341-349.

Bichet, D. G., \& Bockenhauer, D. (2016). Genetic forms of nephrogenic diabetes insipidus (NDI): Vasopressin receptor defect (X-linked) and aquaporin defect (autosomal recessive and dominant). Best Practice and Research. Clinical Endocrinology and Metabolism, 30(2), 263-276.

Bockenhauer, D., \& Bichet, D. G. (2015). Pathophysiology, diagnosis and management of nephrogenic diabetes insipidus. Nature reviews. Nephrology, 11(10), 576-588.

Boyden, L. M., Choi, M., Choate, K. A., Nelson-Williams, C. J., Farhi, A., Toka, H. R., Tikhonova, I. R., Bjomson, R., Mane, S. M., Colussi, G., Lebel, M., Gordon, R. D., Semmekrot, B. A., Poujol, A., Välimäki, M. J., De Ferrari, M. E., Sanjad, S. A., Gutkin, M., Karet, F. E., Tucci, J. R., Stockigt, J. R., KepplerNoreuil, K. M., Porter, C. C., Anand, S. K., Whiteford, M. L., Davis, I. D., Dewar, S. B., Bettinelli, A., Fadrowski, J. J., Belsha, C. W., Hunley, T. E., Nelson, R. D., Trachtman, H., Cole, T. R., Pinsk, M., Bockenhauer, D., Shenoy, M., Vaidyanathan, P., Foreman, J. W., Rasoulpour, M., Thameem, F., AlShahrouri, H. Z., Radhakrishnan, J., Gharavi, A. G., Goilav, B., \& Lifton, R. P. (2012). Mutations in kelch-like 3 and cullin 3 cause hypertension and electrolyte abnormalities. Nature, 22, 482(7383), 98-102.

Cheek, D. B., \& Perry, J. W. (1958). A salt wasting syndrome in infancy. Archives of Disease in Childhood, 33(169), 252-256.

Cheung, P. W., Nomura, N., Nair, A. V., Pathomthongtaweechai, N., Ueberdiek, L. Lu, H. A., Brown, D., \& Bouley, R. (2016). EGF receptor inhibition by Erlotinib increases aquaporin 2-Mediated renal water reabsorption. Journal of the American Society of Nephrology, 27(10), 3105-3116.

Deen, P. M. T., Van Os, C. H., \& Knoers, N. V. A. M. (2009). Nephrogenic diabetes insipidus: Aquaporin-2 defect. In: Lifton, R. P., Somlo, S., Giebsch, G., \& Seldin, D. W. (Eds.). Genetic diseases of the kidney. Elsevier. Pp. 311-362.

Dolezel, Z., Starha, J., Novotna, D., \& Dostalkova, D. (2004). Secondary pseudohypoaldosteronism in an infant with pyelonepßriratsslavské Lekárske Listy 105(12), 435-437.

Elsas, L. J., \& Rosenberg, L. E. (1969). Familial renal glycosuria: A genetic reappraisal of hexose transport by kidney and intestine. The Journal of Clinical Investigation, 48, 1845-1854. 
Geary, D. F., \& Schaefer, F. (Eds.). (2008). The kidney: Comprehensive pediatric nephrology. In: Bockenhauer, D. Diabetes Insipidus. MOSBY. Pp. 489-498.

Geller, D. S. (2005). Mineralocorticoid resistance. Clinical Endocrinology, 62(5), 513-520.

Geller, D. S., Zhang, J., Zennaro, M. C., Vallo-Boado, A., Rodriguez-Soriano, J., Furu, L., Haws, R., Metzger, D., Botelho, B., Karaviti, L., Haqq, A. M., Corey, H., Janssens, S., Corvol, P., \& Lifton, R. P. (2006). Autosomal dominant pseudohypoaldosteronism type 1: Mechanisms, evidence for neonatal lethality, and phenotypic expression in adults. Journal of the American Society of Nephrology, 17(5), 1429-1436.

Gordon, R. D., Geddes, R. A., Pawsey, C. G., \& O’Halloran, M. W. (1970). Hypertension and severe hyperkalaemia associated with suppression of renin and aldosterone and completely reversed by dietary sodium restriction. Australasian Annals of Medicine, 19(4), 287-294.

Jakobsson, B., \& Berg, U. (1994). Effect of hydrochlorothiazide and indomethacine treatment on renal function in nephrogenic diabetes insipidus. Acta Paediatrica, 83(5), 522-525.

Kavanagh, C., \& Uy, N. S. (2019). Nephrogenic diabetes insipidus. Pediatric Clinics of North America, 66(1), 227-234.

Kerem, E., Bistritzer, T., Hanukoglu, A., Hofmann, T., Zhou, Z., Bennett, W., MacLaughlin, E., Barker, P., Nash, M., Quittell, L., Boucher, R., \& Knowles, M. R. (1999). Pulmonary epithelial sodium-channel dysfunction and excess airway liquid in pseudohypoaldosteronism. The New England Journal of Medicine, 341(3), 156-162.

Khachadurian, A. K., \& Khachadurian, L. A. (1964). The inheritance of renal glycosuria. American Journal of Human Genetics, 16, 189-194.

Kilchlechner, V., Koller, D. Y., Seidl, R., \& Waldhauser, F. (1999). Treatment of nephrogenic diabetes insipidus with hydrochlorthiazide and amiloride. Archives of Disease in Childhood, 80, 548-552.

Klein, J. D., Fröhlich, O., Blount, M. A., Martin, C. F., Smith, T. D., \& Sands, J. M. (2006). Vasopressin increases plasma membrane accumulation of urea transporter UT-A1 in rat inner medullary collecting ducts. Journal of the American Society of Nephrology, 17(10), 2680-2686.

Klein, J. D., Wang, Y., Blount, M. A., Molina, P. A., LaRocque, L. M., Ruiz, J. A., \& Sands, J. M. (2016). Metformin, an AMPK activator, stimulates the phosphorylation of aquaporin 2 and urea transporter A1 in inner medullary collecting ducts. American Journal of Physiology, Renal Physiology, 310(10), F1008-1012.

Knoers, N., \& Monnens, L. A. (1990). Amiloride-hydrochlorothiazide versus indomethacin-hydrochlorothiazide in the treatment of nephrogenic diabetes insipidus. The Joumal of Pediatrics, 117(3), 499-502.

Kuhnle, U. (1997). Pseudohypoaldosteronism: Mutation found, problem solved? Molecular and Cellular Endocrinology, 133(2), 77-80.

Kwon, T. H., Frøkiaer, J., Knepper, M. A., \& Nielsen, S. (1998). Reduced AQP1, -2, and -3 levels in kidneys of rats with CRF induced by surgical reduction in renal mass. The American Journal of Physiology, 275(5), F724-741.

Lee, Y. W. (2013). Clinical and genetic analysis in a patient with primary renal glucosuria: Identification of a novel mutation in the SLC5A2 gene. Experimental and Therapeutic Medicine, 6(6), 1532-1534.

Lewis, A. A., Wolstenhome, G. E., \& Reubi, F. (1954). Glucose titration in renal glycosuria. In: Lewis, A. A., \& Wolstenhome, G. E. (Eds.). CIBA Foundation Symposium on the Kidney. Churchill, Ltd., London. Pp. 96-106.

Li, J. H., Chou, C. L., Li, B., Gavrilova, O., Eisner, C., Schnermann, J., Anderson, S. A., Deng, C. X., Knepper, M. A., \& Wess, J. (2009). A selective EP4 PGE2 receptor agonist alleviates disease in a new mouse model of X-linked nephrogenic diabetes insipidus. The Journal of Clinical Investigation, 119(10), 3115-3126.

Li, S., Yang, Y., Huang, L., Kong, M., \& Yang, Z. (2019). A novel compound heterozygous mutation in SLC5A2 contributes to familial renal glucosuria in a Chi- nese family, and a review of the relevant literature. Molecular Medicine Reports, 19(5), $4364-4376$.

Lojman, J., Cygin, A. N., \& Sarkisjan, A. A. (Eds.). (2010). Detskaja nefrologija [Children's nephrology]. Litterra, Moscow (in Russian).

Maruyama, K., Watanabe, H., \& Onigata, K. (2002). Reversible secondary pseudohypoaldosteronism due to pyelonephritis. Pediatric Nephrology, 17(12), 1069-1070.

Miranda, C. A., Lee, J. W., Chou, C. L., \& Knepper, M. A. (2014). Tolvaptan as a tool in renal physiology. American Journal of Physiology, Renal Physiology, 306(3), F359-366.

Morello, J. P., \& Bichet, D. G. (2001). Nephrogenic diabetes insipidus. Annual Review of Physiology, 63, 607-630.

Ocal, G., Berberoğlu, M., Adiyaman, P., Cetinkaya, E., Ekim, M., Aycan, Z., \& Evliyaoğlu, O. (2001). Osteopetrosis, renal tubular acidosis without urinary concentration abnormality, cerebral calcification and severe mental retardation in three Turkish brothers. Journal of Pediatric Endocrinology and Metabolism, 14(9), 1671-1677.

Oemar, B. S., Byrd, D. J., \& Brodehl, J. (1987). Complete absence of tubular glucose reabsorption: A new type of renal glucosuria (type 0). Clinical Nephrology, 27, $156-160$.

Osmanov, I. M., Zaharova, I. N., Kol'be, O. B., Mumladze, J. B., Bekmurzaeva, G. B., \& Tambieva, E. V. (2018). Pervichnye tubulopatii [Primary tubulopathies]. Rossiyskiy Vestnik Perinatologii i Pediatrii, 63(1), 81-89 (in Russian).

Paver, W. K., \& Pauline, G. J. (1964). Hypertension and hyperpotassaemia without renal disease in a young male. The Medical Journal of Australia, 22(2), 305-306.

Prié, D. (2014). Familial renal glycosuria and modifications of glucose renal excretion. Diabetes and Metabolism, 6(Suppl. 1), 12-16.

Riepe, F. G., Finkeldei, J., de Sanctis, L., Einaudi, S., Testa, A., Karges, B., Peter, M., Viemann, M., Grötzinger, J., Sippell, W. G., Fejes-Toth, G., \& Krone, N. (2006). Elucidating the underlying molecular pathogenesis of NR3C2 mutants causing autosomal dominant pseudohypoaldosteronism type 1 . The Journal of Clinical Endocrinology and Metabolism, 91(11), 4552-4561.

Santer, R., \& Calado, J. (2010). Familial renal glucosuria and SGLT2: From a mendelian trait to a therapeutic target. Clinical Joumal of the American Society of Nephrology, 5(1), 133-141.

Schaedel, C., Marthinsen, L., Kristoffersson, A. C., Komfält, R., Nilsson, K. O., Orlenius, B., \& Holmberg, L. (1999). Lung symptoms in pseudohypoaldosteronism type 1 are associated with deficiency of the alpha-subunit of the epithelial sodium channel. The Journal of Pediatrics, 135(6), 739-745.

Schofer, O., Beetz, R., Bohl, J., Bornemann, A., Oepen, J., \& Spranger, J. (1990). Mental retardation syndrome with renal concentration deficiency and intracerebral calcification. European Journal of Pediatrics, 149(7), 470-474

Smijan, O. I., Romanjuk, O. K., Binda, T. P., Sichnenko, P. I., Gorban', V. A., \& Saj, V.P. (2010). Klinichnij vipadok psevdogipoal'dosteronizmu [Clinical case of pseudohypoaldosteronism]. Visnik Sums'kogo Derzhavnogo Universytetu, Serija Medicina, 2, 158-162 (in Ukrainian).

Urakami, T., Yoda, M., Yoshida, K., Mine, Y., Aoki, M., \& Suzuki, J. (2018). Renal glucosuria in schoolchildren: Clinical characteristics. Pediatrics International, 60(1), 35-40.

Vehaskart, V. M. (2007). Developmental origins of adult hypertension: New insights into the role of the kidney. Pediatric Nephrology, 22, 490-495.

Wright, E. M., Hirayama, B. A., \& Loo, D. F. (2007). Active sugar transport in health and disease. Journal of Internal Medicine, 261(1), 32- 43.

Yu, L., Hou, P., Lv, J. C., Liu, G. P., \& Zhang, H. (2015). Novel SLC5A2 variants contribute to renal glucosuria in Chinese families: Abnormal expression and dysfunction of variant SLC5A2. Human Mutation, 36(1), 79-86.

Zennaro, M. C., \& Lombès, M. (2004). Mineralocorticoid resistance. Trends in Endocrinology and Metabolism, 15(6), 264-270. 